\title{
Pulmonary concentrations of dirithromycin and erythromycin during acute exacerbation of mild chronic obstructive pulmonary disease
}

\author{
M.G. Matera*, M.A. Tufano**, M. Polverino+, \\ F. Rossi*, M. Cazzola*++
}

Pulmonary concentrations of dirithromycin and erythromycin during acute exacerbation of mild chronic obstructive pulmonary disease. M.G. Matera, M.A. Tufano, M. Polverino, F. Rossi, M. Cazzola. (CERS Journals Ltd 1997.

ABSTRACT: We compared the concentrations of dirithromycin and erythromycin at steady state in serum and the intrapulmonary region in patients suffering from acute exacerbation of mild chronic obstructive pulmonary disease.

Twenty patients received dirithromycin, $500 \mathrm{mg}$ given orally once daily for five consecutive days. The other 20 patients were treated with erthromycin base, which was administered orally four times daily at a total daily dose of $1000 \mathrm{mg}$ for seven days. All patients were divided into eight groups, with five subjects in each group, according to sampling times $(2,4,8$, and 24 hrs after the last dose) and treatment.

After the erthromycin treatment mean serum concentrations were higher than those of dirithromycin treatment mean serum concentrations were higher than those of dirithromycin for upto 4 hours, but they were undetectable 24 hours after the last dose. At all time periods, the concentrations of dirithromycin in bronchial secretion, bronchial mucosa and epithelial lining fluid were greater than the concentration in serum. Concentrations of erythromycin were always lower than those of dirithromycin in the explored pulmonary sites.

Our data demonstrated that a five day course of $500 \mathrm{mg}$ of dirithromycin once daily induced higher concentrations and longer persistence in the various potential sites of pulmonary infection than a seven day course of $250 \mathrm{mg}$ of erythromycin every 6 hrs. The shorter duration of therapy and the once daily dosing with good efficacy against common respiratory pathogens would be advantageous for patients and would be likely to promote better patient compliance and acceptability.

Eur Respir J., 1997; 10: 98-103.

\author{
*Istituto di Farmacologia e Tossicologia, \\ and **Cattedra di Microbiologia Clinica, \\ Seconda Università Napoletana, Napoli, \\ Italy. +Servizio di Fisiopatologia Respira- \\ toria, Ospedale S. Maria dell'Olmo, Cava \\ dei Tirreni, Italy. ${ }^{+}$Divisione di Pneumologia \\ ed Allergologia e Settore di Farmacologia \\ Clinica Respiratoria, Ospedale A. Cardarelli, \\ Napoli, Italy. \\ Correspondence: M. Cazzola \\ Via del Parco Margherita 24 \\ 80121 Napoli \\ Italy \\ Keywords: Dirithromycin \\ erythromycin \\ exacerbations of chronic obstructive \\ pulmonary disease \\ pulmonary penetration \\ Received: March 291996 \\ Accepted after revision September 25 \\ 1996 \\ This work was carried out in the Servizio \\ di Fisiopatologia Respiratoria at the Osped- \\ ale S. Maria dell'Olmo, Cava dei Tirreni, \\ Italy, with funds provided by Lilly Labora- \\ tories, Indianapolis, IN, USA.
}

Many factors influence the choice of antibiotic and determine the optimum regimen. One such factor is tissue penetration. It is of primary importance to have a dosing regimen that maintains the free drug concentration above the minimum inhibitory concentration (MICs) for a reasonable period of time, in order to target the pathogens of the common lower respiratory tract infections with antimicrobials. The potential efficacy of an antibiotic in the treatment of chest infections may be estimated by measuring the concentration of the drug at potential sites of infection, other than serum [1].

Dirithromycin is a new macrolide antibiotic with unusual pharmacokinetics, characterized by a rapid and extensive distribution to the extravascular tissues and a slow but constant elimination from these tissues into the vascular spaces $[2,3]$. It possesses antimicrobial activity comparable to that of erythromycin in vitro, but is more active than erythromycin in vivo, which may be attributable to the persistence of antimicrobial activity in the tissues $[4,5]$. Dirithromycin serum half-life is longer than that of erythromycin, and some lines of evidence have indicated tissue concentrations to be higher after oral dirithromycin than after oral erythromycin [4].
Several studies have shown that dirithromycin, 500 $\mathrm{mg}$ once daily for a minimum of 7 days, and erythromycin, 1,000 mg four times daily $[6,7]$ are comparable in the treatment of acute exacerbation of chronic bronchitis. Recently, a dirithromycin treatment of less than 7 days duration has also been demonstrated to be possible for acute bacterial exacerbation of chronic bronchitis. In fact, a 5 day, once daily, dirithromycin regimen $\left(500 \mathrm{mg} \cdot \mathrm{day}^{-1}\right)$ was as safe and as effective as a 7 day, four times daily, erythromycin regimen $\left(1,000 \mathrm{mg} \cdot \mathrm{day}^{-}\right.$ 1) (Salisbury et al. abstract presented at the 33rd ICAAC, New Orleans, 1993; Jones et al. abstract presented at the 34th ICAAC, Orlando, 1994).

The purpose of the present study was to compare the concentrations of these two macrolides during steady state in serum and in the intrapulmonary region, at specified intervals for $24 \mathrm{~h}$ following administration of the last dose of drug in patients suffering from acute exacerbation of mild, chronic obstructive pulmonary disease (COPD). In addition, we aimed to find out whether a different pulmonary pharmacokinetic behaviour might explain the response to this shorter-term treatment with dirithromycin. 


\section{Patients and methods}

In total, 40 patients suffering from acute exacerbation of mild COPD were enrolled in this open-label study. Ethics Committee approval of the study was obtained, and all patients provided informed consent. The diagnosis of mild COPD was consistent with the standards of the consensus statement of the European Respiratory Society (ERS) [8] and was established on the basis of clinical history, physical findings, (spirometry forced expiratory volume in one second (FEV1) $>70 \%$ of predicted in the presence of obstruction assessed as FEV1/vital capacity (VC) $<88 \%$ pred in males or $<89 \%$ pred in females). Acute exacerbation was established as an alteration in the quiescent state of the patient, with an increase in frequency of cough, increase in quantity and/or purulence of sputum, presence of pulmonary crackles or rhonchi, and isolation of pathogens. Using the system of BALL et al. [9] to stratify subjects suffering from acute exacerbation of chronic bronchitis, all patients could be graded into stage II (chronic bronchitis with dyspnoea plus increased sputum volume and purulence).

During a patient's initial visit, the cellular composition and bacterial flora of the sputum were determined by use of a wet [10] preparation and a Gram stain. Patients excluded were those that were: pregnant or lactating; known to be allergic to macrolides, atropine or diazepam; concomitantly using other antibiotics, carbamazepine, warfarin, ergotamines, digoxin or cyclosporin; with clinically significant liver dysfunction; suffering from any condition including significant underlying disease (particularly coexistent cardiopulmonary factors) or concomitant infection which, in the opinion of the investigator, could preclude evaluation of response or inability of the patient to undergo bronchoscopy. The finding in sputum of a predominance of polymorphonuclear eosinophils or the presence of swollen bronchial epithelial cells with inclusion bodies excluded patients from the study. The absence of an increase of bacterial flora on Gram stain also excluded patients from the study.

Twenty patients were randomized to the dirithromycin group, the other 20 patients received erythromycin base. Dirithromycin was administered orally at a dose of 500 $\mathrm{mg}$ (two $250 \mathrm{mg}$ tablets) every $24 \mathrm{~h}$, for a total of five doses. Erythromycin was administered orally at a dose of $250 \mathrm{mg}$ every $6 \mathrm{~h}$, for a total of 28 doses. All patients were divided into eight groups, with five subjects in each group, according to sampling times $(2,4,8$ and $24 \mathrm{~h}$ after the last dose) and treatment. There were no significant differences in age, gender, ethnic origin, height or weight between groups. Table 1 outlines the baseline demographic characteristics of the patients.

Fibreoptic bronchoscopy and bronchoalveolar lavage (BAL) were performed under local anaesthesia $(160 \mathrm{mg}$ of $4 \%$ nebulized lignocaine) supplemented by $5 \mathrm{mg}$ intravenous diazepam and $1 \mathrm{mg}$ of intramuscular atropine. Following routine inspection of the respiratory tract and aspiration of bronchial secretions, the tip of the bronchoscope was wedged into a subsegmental bronchus of the lingula or the right middle lobe. Lavage was performed with $200 \mathrm{~mL}$ of sterile $0.9 \mathrm{~N}$ saline divided into 5 equal aliquots. After injection of the saline, the fluid was suctioned with a negative pressure of $50-100 \mathrm{mmHg}$. The aspirate from the first $40 \mathrm{~mL}$ of the aliquot was
Table 1. - Patients characteristics

\begin{tabular}{lcccc}
\hline $\begin{array}{l}\text { Time after } \\
\text { last dose } \mathrm{h}\end{array}$ & $\begin{array}{c}\text { Sex } \\
(\mathrm{M} / \mathrm{F})\end{array}$ & $\begin{array}{c}\text { Age } \\
\text { yrs }\end{array}$ & $\begin{array}{c}\text { Height } \\
\mathrm{cm}\end{array}$ & $\begin{array}{c}\text { Weight } \\
\mathrm{kg}\end{array}$ \\
\hline $\begin{array}{l}\text { Dirithromycin } \\
2\end{array}$ & $3 / 2$ & $58 \pm 11$ & $169 \pm 4$ & $77 \pm 7$ \\
4 & $5 / 0$ & $63 \pm 7$ & $170 \pm 2$ & $79 \pm 6$ \\
8 & $5 / 0$ & $54 \pm 9$ & $169 \pm 2$ & $80 \pm 4$ \\
24 & $5 / 0$ & $66 \pm 6$ & $163 \pm 4$ & $70 \pm 6$ \\
Erythromycin & & & & \\
2 & $5 / 0$ & $64 \pm 5$ & $168 \pm 4$ & $76 \pm 4$ \\
4 & $4 / 1$ & $60 \pm 7$ & $166 \pm 5$ & $78 \pm 6$ \\
8 & $4 / 1$ & $62 \pm 6$ & $168 \pm 3$ & $74 \pm 6$ \\
24 & $5 / 0$ & $64 \pm 5$ & $167 \pm 4$ & $77 \pm 8$ \\
\hline
\end{tabular}

Values are presented as mean \pm SD.

discarded. The pooled sample was collected in a sterile sputum trap. Four to six bronchial biopsies were then taken from subcarinal mucosa. They were weighed, a volume of ice-cold phosphate buffer was added, and this was ultrasonicated on ice for $1 \mathrm{~min}$. Blood was drawn simultaneously for dirithromycin or erythromycin and urea assay.

Antimicrobial concentration in the epithelial (alveolar) lining fluid (ELF) was derived from the following relationship [11]:

$$
\text { macrolide }_{\mathrm{ELF}}=\text { macrolide } \mathrm{BAL} \times V_{\mathrm{BAL}} / V_{\mathrm{ELF}}
$$

where $V_{\text {BAL }}$ is the volume of aspirated BAL fluid and $V_{\text {ELF }}$ is the volume of ELF sampled by the BAL. Estimation of the amount of ELF was determined by the urea dilution method [12]. $V_{\text {ELF }}$ was derived from the following relationship:

$$
V_{\mathrm{ELF}}=V_{\mathrm{BAL}} \times(\text { UreabaL } / \text { Ureaserum })
$$

The urea concentration in BAL fluid was corrected for possible contamination with urea from blood. To determine the amount of urea from blood, the ratio of erythrocytes in BAL fluid to erythrocytes in blood was used.

The BAL fluid was immediately centrifuged at $500 \times \mathrm{g}$ for $5 \mathrm{~min}$ in a refrigerated centrifuge to separate the cellular and fluid phases. Immediate centrifugation was necessary to minimize any diffusion of the antibiotic from the alveolar cells into the lavage fluid. The BAL supernatant was freeze-dried and then resuspended in distilled water to yield a 10 fold concentration. It was assayed for urea using the method of BALDWIN et al. [13]. It should be noted that in all serum and tissue samples collected after administration of dirithromycin, the antibiotic activity measured was the erythromycylamine concentration [2, 3]. Concentrations of erythromycylamine and erythromycin were measured by the agar diffusion method, with Micrococcus luteus American type culture collection (ATCC) 9341 as the test microorganism, and antibiotic agar No. 1 at $\mathrm{pH}$ 8.5. Analytical standards of erythromycylamine and erythromycin were prepared in pooled normal human serum and in phosphate buffer ( $\mathrm{pH}$ 8.0) solution for bronchial secretions, ELF and biopsy samples. The erythromycylamine between assay coefficient of variation was $10.7 \%$ and the lower limit of sensitivity was $0.03 \mu \mathrm{g} \cdot \mathrm{mL}^{-1}$. The erythromycin between assay coefficient of variation was $7.6 \%$ and lower limit of sensitivity was $0.04 \mu \mathrm{g} \cdot \mathrm{mL}^{-1}$. 
Table 2. - MICs of dirithromycin and erythromycin for relevant respiratory pathogens

\begin{tabular}{|c|c|c|c|c|}
\hline \multirow[b]{2}{*}{ Organism } & \multicolumn{2}{|c|}{ Dirithromycin } & \multicolumn{2}{|c|}{ Erythromycin } \\
\hline & $\begin{array}{c}\text { MIC50 } \\
\mu \mathrm{g} \cdot \mathrm{mL}^{-1}\end{array}$ & $\begin{array}{c}\mathrm{MIC} 90 \\
\mu \mathrm{g} \cdot \mathrm{mL}^{-1}\end{array}$ & $\begin{array}{c}\text { MIC50 } \\
\mu \mathrm{g} \cdot \mathrm{mL}^{-1}\end{array}$ & $\begin{array}{c}\mathrm{MIC} 90 \\
\mu \mathrm{g} \cdot \mathrm{mL}^{-1}\end{array}$ \\
\hline Streptococcus pneumoniae & $0.06-0.25$ & 0.12 & $0.03-0.12$ & $0.03-0.25$ \\
\hline Moraxella catarrhalis & $0.12-1.0$ & $0.25-2.0$ & $0.12-0.50$ & $0.25-0.50$ \\
\hline Haemophilius influenzae & $0.25-8.0$ & 8.0 & $0.25-4.0$ & 4.0 \\
\hline Staphylococcus aureus & $0.25-1.0$ & 0.25 to $>128$ & $0.12-0.5$ & 0.12 to $>128$ \\
\hline
\end{tabular}

MIC50 and MIC90: minimum concentration required to produce $50 \%$ and $90 \%$ inhibition, respectively. (From DerRIENNIC [15]).

\section{Results}

All 40 subjects recruited for the study underwent and successfully completed the bronchoscopy and BAL. There were no major adverse events.

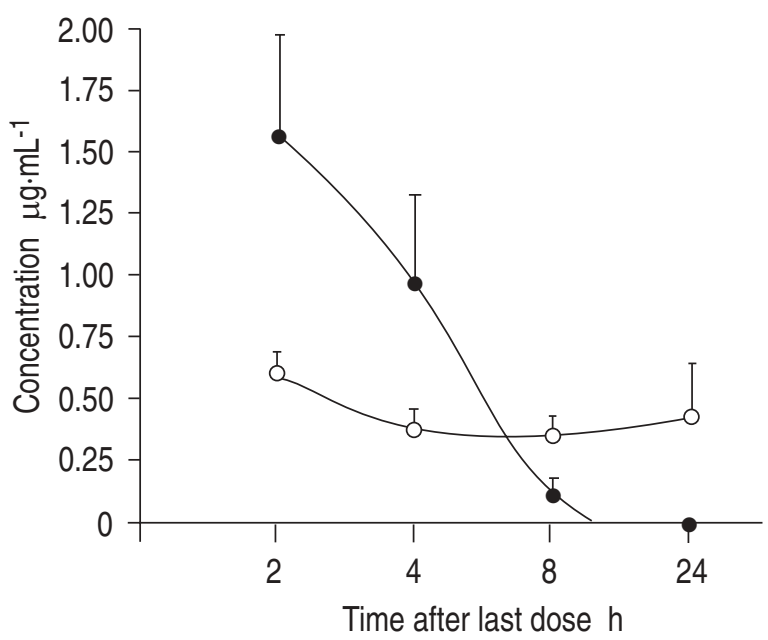

Fig. 1. - Concentrations of dirithromycin (-O-) and erythromycin (- - ) in serum at each time-point after the last dose. Values are presented as mean $\pm \mathrm{SD}$. Dirithromycin was administered orally at a dose of $500 \mathrm{mg}$ (two $250 \mathrm{mg}$ tablets) every $24 \mathrm{~h}$ for a total of five doses. Erythromycin was administered orally at a dose of $250 \mathrm{mg}$ every $6 \mathrm{~h}$ for a total of 28 doses. Five patients in each group.

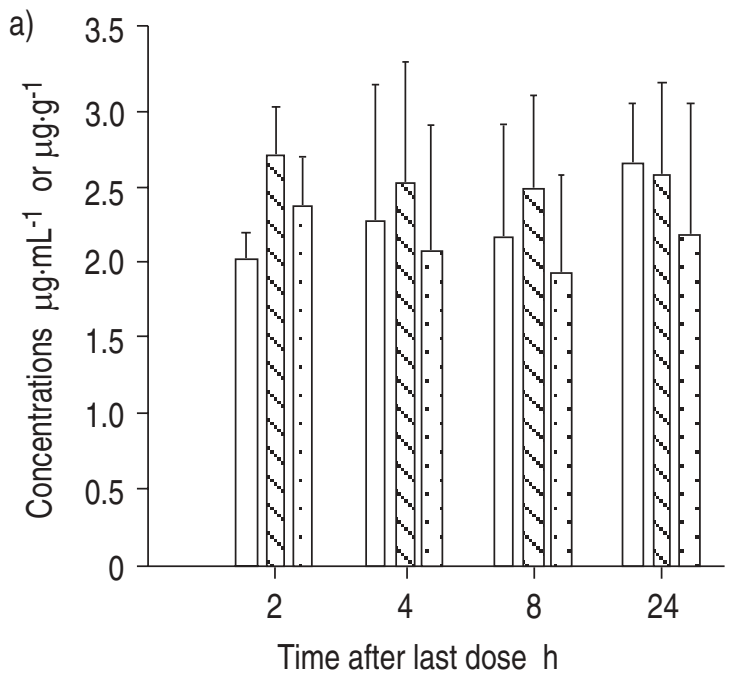

Following the dirithromycin 5 day therapy, mean serum concentrations remained low, although they were within the range of minimum inhibitory concentrations required to produce 50\% (MIC50) and 90\% inhibition (MIC90) for Streptococcus pneumoniae and Moraxella catarrhalis for up to $24 \mathrm{~h}$ after the last dose (table 2 and fig. 1). In all other samples, mean concentrations were higher than MICs for many relevant respiratory microorganisms [14] and intracellular pathogens [15] (fig. 2 and table 2), but not for Haemophilus influenzae. However, a large interindividual variability of concentrations was observed. After the erythromycin 7 day treatment, mean serum concentrations were higher than those of dirithromycin for up to $4 \mathrm{~h}$, but they were undetectable $24 \mathrm{~h}$ after the last dose (fig. 1).

At all time-points, the concentrations of dirithromycin in bronchial secretion, bronchial mucosa and ELF were greater than the concentrations in serum. Concentrations of erythromycin were always lower than those of dirithromycin in the pulmonary sites explored (highest values in bronchial secretions, bronchial mucosa, and ELF were $0.82 \mu \mathrm{g} \cdot \mathrm{mL}^{-1}, 1.75 \mu \mathrm{g} \cdot \mathrm{g}^{-1}$, and $0.97 \mu \mathrm{g} \cdot \mathrm{mL}^{-1}$, respectively, after erythromycin, and $2.67 \mu \mathrm{g} \cdot \mathrm{mL}^{-1}, 2.71 \mu \mathrm{g} \cdot \mathrm{g}^{-1}$ and $2.37 \mu \mathrm{g} \cdot \mathrm{mL}^{-1}$ respectively, after dirithromycin) (fig. 2). Figure 2 also shows that a steady state of drug concentration had been reached in the lungs after five doses of dirithromycin, but not after 28 doses of erythromycin.

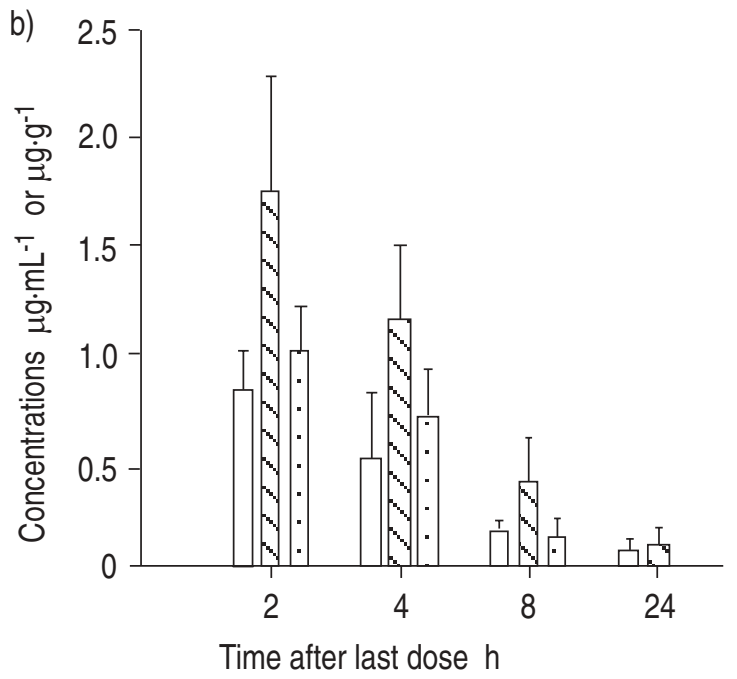

Fig. 2. - Concentrations of: a) dirithromycin; b) erythromycin in bronchial secretions ( $\square$ ), bronchial mucosa ( $\square$ ), and ELF ( $\square$ ) at each time-point after the last dose. Values are presented as mean \pm sD. Dirithromycin was administered orally at a dose of $500 \mathrm{mg}$ (two $250 \mathrm{mg}$ tablets) every $24 \mathrm{~h}$ for a total of five doses. Erythromycin was administered orally at a dose of $250 \mathrm{mg}$ every $6 \mathrm{~h}$ for a total of 28 doses. Five patients in each group. ELF: epithelial lining fluid. 


\section{Discussion}

This study demonstrated that a 5 day course of 500 $\mathrm{mg}$ of dirithromycin, once daily, induced higher concentrations and longer persistence in the various potential sites of pulmonary infection than a 7 day course of $250 \mathrm{mg}$ of erythromycin, every $6 \mathrm{~h}$. There is no doubt that the shorter duration of therapy and the once daily dosing, with good efficacy against common respiratory pathogens, would be advantageous for patients and would be likely to promote better patient compliance and acceptability.

We have used the microbiological assay to determine macrolide concentrations in tissue homogenates and fluids, although microbiological assays express total bioactivity and metabolites, such as erythromycylamine, are not detectable [3]. However, the results obtained using high performance liquid chromatography (HPLC) to assay dirithromycin concentrations in tissue samples were similar to the findings of studies which used a microbiological assay [4]. We emphasize that the HPLC assay indicated that the antimicrobial activity in lung tissue was related to erythromycylamine rather than to dirithromycin [4]. This finding not a surprising since dirithromycin cannot be detected in plasma, urine or faeces after oral administration. and is only transiently detected shortly after i.v. administration [2,3]; the drug is rapidly converted in vivo and in vitro by nonenzymatic hydrolysis to erythromycylamine, which has antimicrobial activity similar to that of the parenteral compound [3]. In rats, after duodenal administration of dirithromycin (30 $\left.\mathrm{mg} \cdot \mathrm{kg}^{-1}\right)$, erythromycylamine was observed in blood, kidneys and lungs; within $1 \mathrm{~h}$ after administration, dirithromycin was no longer detected in blood and lungs tissues, and $8 \mathrm{~h}$ after administration, only erythromycylamine was found in kidneys and lungs [15].

We must also stress these patients received erythromycin base and not erythromycin esters, because the free base is the only form to be biologically active and, therefore, measured in bioassays; and in vitro hydrolysis of erythromycin esters to erythromycin base occurs (to an unknown degree) during the assay procedure, resulting in an overestimation of the bioactive level [16]. Moreover, lidocaine interferes with the chromatographic determination of erythromycin [17].

Recent data [4] revealed that bronchial secretions contain a notable amount of antimicrobial activity (1.04 $\left.\mu \mathrm{g} \cdot \mathrm{mL}^{-1}\right) 3 \mathrm{~h}$ after a single $500 \mathrm{mg}$ dirithromycin dose; the prolonged half-life of the drug maintains significant concentrations of $1.3 \pm 1.6 \mu \mathrm{g} \cdot \mathrm{mL}^{-1} 12$ hours postdose, with a slow decrease, parallel to that in serum. Another study demonstrated that most concentrations of dirithro-mycin in bronchial mucosa exceed $1 \mu \mathrm{g} \cdot \mathrm{mL}^{-1}$ 4-24 h following a single 250 or $500 \mathrm{mg}$ dose. After multiple doses, at all sampling times (4, 12 and $24 \mathrm{~h}$ ) concentrations were in the range $1.30-1.95 \mu \mathrm{g} \cdot \mathrm{mL}^{-1}$.

In the present study, a surprisingly high mean concentration of dirithromycin was found in bronchial secretions at all sampling times (range 2.04-2.67 $\mu \mathrm{g} \cdot \mathrm{mL}^{-1}$ ) without a decrease parallel to the serum levels. These data also demonstrated that the concentrations of this macrolide in bronchial mucosa were in the range 2.50 $2.71 \mu \mathrm{g} \cdot \mathrm{mL}^{-1}$, values which are higher than those in other studies. We observed a notable range of individual concentrations in the two sites explored, but a rather stable concentration as a function of time. It is possible that inflammation affected the dirithromycin and erythromycin levels in bronchial secretions and mucosa. In fact, inflammation itself is likely to have a considerable effect on the ability of antibiotics to cross barriers [18]. The present patients were clinically similar; however, it is well-known that the type, degree and time course of inflammation may vary greatly from patient to patient, and in an individual patient during the course of disease [19]. This factor is virtually unassessable and might have contributed substantially to the interindividual variability of concentrations that were observed. We do not believe that this interindividual variability arose from the short regimen of 5 days, because we have demonstrated that dirithromycin is concentrated in each of the potential sites of infection in the lung for up to 3 days after a 5 day course of therapy [20]. Moreover, the degree of penetration of macrolides into the cell varies widely between subjects [21].

Studies with erythromycin showed that the concentrations measured in bronchial secretions were 0.59-0.89 $\mu \mathrm{g} \cdot \mathrm{mL}^{-1}$ after a $1,000 \mathrm{mg}$ single dose [22, 23], and 1.05 $\mu \mathrm{g} \cdot \mathrm{mL}^{-1}$ after $1,000 \mathrm{mg}$ multiple dose [24]. Another study showed a mean level of erythromycin in bronchial mucosa of $7.20 \pm 4.30 \mu \mathrm{g} \cdot \mathrm{mL}^{-1} 4.3 \mathrm{~h}$ after multiple oral doses of $500 \mathrm{mg}$ erythromycin [25].

The present study confirmed the low concentrations of erythromycin in bronchial secretions $\left(0.82 \mu \mathrm{g} \cdot \mathrm{mL}^{-1}\right.$ at $2 \mathrm{~h}$ after the last dose) and demonstrated that this macrolide, at the dosing regimen of $250 \mathrm{mg}$ every $6 \mathrm{~h}$ in patients suffering from an acute exacerbation of chronic bronchitis, achieved levels which were higher in bronchial mucosa than in bronchial secretions.

Concentrations of dirithromycin and erythromycin in bronchial mucosa were greater than those in ELF, but this was not surprising since the concentration in the bronchial mucosa represents the mean of the concentration in the extracellular and intracellular fluid, while ELF represents the concentrations in the extracellular fluid only [1]. We emphasize that this study found high and sustained levels of dirithromycin in ELF but low concentrations of erythromycin, which was undetectable $24 \mathrm{~h}$ after the last dose is this pulmonary site. In contrast, BAughman et al. [26] were unable to measure dirithromycin or erythromycin in unconcentrated BAL fluid from patients with acute exacerbation of chronic bronchitis $5 \mathrm{~h}$ after the first morning dose of the fifth day of treatment, but they found high levels of dirithromycin in alveolar macrophages. It is possible that this difference was due to the duration of bronchoscopy; in fact, the process causes antibiotic efflux from cells to allow full equilibrium between BAL fluid and the cell component when it is of more than $10 \mathrm{~min}$ duration [27]. BAUGHMAN et al. [26] completed the BAL in less than $1 \mathrm{~min}$, whereas we always took a longer time (3 min) for complete lavage and, in any case, we were unable to obtain BAL fluid and to separate cells in less than $12-15 \mathrm{~min}$. It is interesting to note that CONTE et al. [17] found that when healthy adults received $250 \mathrm{mg}$ erythromycin every $6 \mathrm{~h}$ for nine doses, the drug was detectable in $\operatorname{ELF}\left(0.8 \mu \mathrm{g} \cdot \mathrm{mL}^{-1}\right)$ at $4 \mathrm{~h}$ following administration of the last dose, but not at 8 or $12 \mathrm{~h}$. 
The present data also showed that dirithromycin serum concentrations, although low, were higher than the minimal concentration required to produce half-maximal inhibition (MIC50) against relevant respiratory pathogens for at least $24 \mathrm{~h}$ after the last dose, while erythromycin serum concentrations were higher than those of dirithromycin in the first hours after the treatment, but were not detectable at $24 \mathrm{~h}$ after the last dose.

Macrolides penetrate into cells and accumulate within the lysosomes, where the protonated species of the molecules are trapped because they ionize in the low $\mathrm{pH}$ of the lysosome [28]. Dirithromycin has been shown to have higher intracellular retention $[26,29]$, probably because this molecule contains two basic sites for protonation, one on the desosamine sugar and the other at the $\mathrm{C} 9$ position of the lactone ring. Its long persistence in the cells may be attributable to this second amino group. The intracellular accumulation may explain the singular pulmonary disposition of dirithromycin after short-term therapy. In fact, it is possible that the high levels seen in the current study in the bronchial mucosa were in lysosomes of tissue macrophages. However, the present data demonstrated that this drug also reached high concentrations at extracellular sites of infection.

The role of antibiotics in the therapy of exacerbations of COPD remains controversial [30], since 4-63\% of acute exacerbations are linked to viruses, and some exacerbations may not be infective in origin but rather represent a fluctuation in the severity of the patient's underlying bronchospasm [1]. However, previous authors have shown antibiotic therapy to be better than placebo for fully developed exacerbations [31, 32], and a meta-analysis of randomized trials of antibiotic therapy for exacerbation of COPD has suggested a small but statistically significant improvement due to antibiotic therapy [33]. Therefore, it seems reasonable to treat patients with COPD and acute respiratory failure with antimicrobial agents, whilst recognizing that only a minority of patients will benefit [1]. In any case, the consensus statement of ERS [8] accepts the pattern of associated repetitive respiratory infections in bronchitis and suggests the use of antibiotics, among other treatment modalities, during the early treatment of exacerbations, regardless of severity, probably in the belief that some benefit may be achieved. The choice of antibiotic should take into account its ability to penetrate into bronchial tissue and secretions [1]. The pharmacokinetic behaviour of dirithromycin may help to explain the favourable responses observed in clinical studies and provide a rational basis for the treatment of patients classified in stage II and, perhaps, in stage III (stage II symptoms plus comorbidity and more than three or four exacerbations per year), according to the severity classification of BALL et al. [9] for exacerbations of chronic bronchitis.

Acknowledgements: The authors acknowledge P. Catalanotti and M. Angrisani for performing the assays and G. Sides and P. Smits for their helpful comments.

\section{References}

1. Cazzola M. Problems and prospectives in the antibiotic treatment of lower respiratory tract infections. Pulm Pharmacol 1994; 7: 139-152.
2. Sides GD, Cerimele BJ, Black HR, Busch U, DeSante KA. Pharmacokinetics of dirithromycin. $J$ Antimicrob Chemother 1993; 31 (Suppl. C): 65-75.

3. DeSante KA. Human pharmacokinetics and bioavailability of dirithromycin. Drugs Today 1995; 31 (Suppl. C): 11-16.

4. Bergogne-Bérézin E. Tissue distribution of dirithromycin: comparison with erythromycin. J Antimicrob Chemother 1993; 31 (Suppl C): 77-87.

5. Cazzola M. Pulmonary pharmacokinetics of dirithromycin allow a 5 day treatment of acute bacterial exacerbation of chronic bronchitis. Drugs Today 1995; 31 (Suppl. C): 17-21.

6. Gaillat J. A multicentre study comparing the safety and efficacy of dirithromycin with erythromycin in the treatment of bronchitis. J Antimicrob Chemother 1993; 31 (Suppl C): 139-151.

7. Sides GD. Clinical efficacy of dirithromycin in acute exacerbation of chronic bronchitis $J$ Antimicrob Chemother 1993; 31 (Suppl. C): 131-138.

8. Siafakas NM, Vermeire P, Pride NB, et al. Optimal assessment and management of chronic obstructive pulmonary disease (COPD). Eur Respir J 1995; 8: 1398-1420.

9. Ball P, Hams JM, Lowson D, Tillotson G, Wilson R. Acute infective exacerbations of chronic bronchitis. $Q$ J Med 1991; 88: 61-68.

10. Chodosh S. Examination of sputum cells. $N$ Engl J Med 1970; 282: 854-857.

11. Valcke Y, Pauwels R, Van der Straeten M. Pharmacokinetics of antibiotics in the lung. Eur Respir J 1990; 3: 715-722.

12. Rennard SI, Basset G, Lecossier D, et al. Estimation of volume of epithelial lining fluid recovered by lavage using urea as a marker of dilution. J Appl Physiol 1986; 60: 532-538.

13. Baldwin DR, Honeybourne D, Wise R. Pulmonary disposition of antimicrobial agents: methodological considerations. Antimicrob Agents Chemother 1992; 36: $1171-1175$.

14. Bauernfeind A. In vitro activity of dirithromycin in comparison with other new and established macrolides. $J$ Antimicrob Chemother 1993; 31 (Suppl C): 39-49.

15. Derriennic M. Antimicrobial activity of dirithromycin. Drugs Today 1995; 31 (Suppl. C): 23-28.

16. Bergogne-Bérézin E. Tissue distribution of macrolide antibiotics. In: Bryskier AJ, Butzler J-P, Neu HC, Tulkens PM, eds. Macrolides: Chemistry, Pharmacology and Clinical Uses. Paris, Arnette Blackwell, 1993; pp. 451-484.

17. Conte JE Jr, Golden JA, Duncan S, McKenna E, Zurlinden E. Intrapulmonary pharmacokinetics of clarithromycin and of erythromycin. Antimicrob Agents Chemother 1995; 39: 334-338.

18. Honeybourne D, Baldwin DR. The site concentrations of antimicrobial agents in the lung. J Antimicrob Chemother 1992; 30: 249-260.

19. Fraser RG, Parè JAP. In: Diagnosis of Diseases of Chest. 2nd edn. Philadelphia, Sauders, 1978; pp. 1360-1363.

20. Cazzola M, Matera MG, Tufano MA, et al. Pulmonary penetration of dirithromycin in patients suffering from acute exacerbation of chronic bronchitis. Pulm Pharmacol 1994; 7: 377-381.

21. Sörgel F, Kinzig M, Naber KG. Physiological disposition of macrolides. In: Bryskier AJ, Butzler J-P, Neu HC, Tulkens PM, eds. Macrolides: chemistry, pharmacology and clinical uses. Paris, Arnette Blackwell, 1993; pp. 421-435.

22. Fraschini F, Braga PC, Copponi V, et al. Tropism of 
erythromycin for the respiratory system. J Med Res 1980; 8 (Suppl. 2): 36-40.

23. Brun Y, Forey F, Gamondes JP. Levels of erythromycin in pulmonary tissue and bronchial mucus compared to those of amoxycillin. J Antimicrob Chemother 1981; 8: 459-466.

24. Bergogne-Bérézin E, Berthelot G, Kafé H, Pierre J, Dournovo $\mathrm{P}$. Influence of a fluidifying agent (bromhexine) on the penetration of antibiotics into respiratory secretions. Int J Clin Pharmacol Res 1985; 5: 341-344.

25. Honeybourne D, Andrews J, Ashby J, Huggins A, Islim I, Wise R. Penetration of bronchial mucosa by erythromycin. Thorax 1988; 43: 861.

26. Baughman RP, DeSante KA, Lanier TL, et al. The penetration of dirithromycin into bronchoalveolar lavage fluid and alveolar macrophages. J Antimicrob Chemother 1994; 33: 1045-1050.

27. Baldwin DR, Wise R, Andrews JM, Honeybourne D. Concentrations of antimicrobials in pulmonary alveolar epithelial lining fluid. Res Clin Forum 1990: 12(4): 103-113.

28. Pechère J-C. Activity of intracellular antibiotics within cells. Medical Masterclasses 1993; 1(3): 24-29.

29. Hand WL, Hand DL. Interactions of dirithromycin with human polymorphonuclear leukocytes. Antimicrob Agents Chemother 1993; 37: 2557-2562.

30. Ball P. Infective pathogenesis and outcomes in chronic bronchitis. Curr Opin Pulm Med 1996; 2: 181-185.

31. Anthonisen NR, Manfreda J, Warren CPW, Hershfeild ES, Harding GKM, Nelson NA. Antibiotic therapy in acute exacerbations of chronic obstructive pulmonary disease. Ann Intern Med 1987; 106: 196-204.

32. Allegra L, Grassi C, Grossi E, Pozzi E. Ruolo degli antibiotici nel trattamento della riacutizzazione della bronchite cronica. Giorn It Mal Tor 1991; 45: 138-148.

33. Saint S, Bent S, Vittinghof E, Grady D. Antibiotics in chronic obstructive pulmonary disease exacerbations. JAMA 1995; 273: 957-960. 